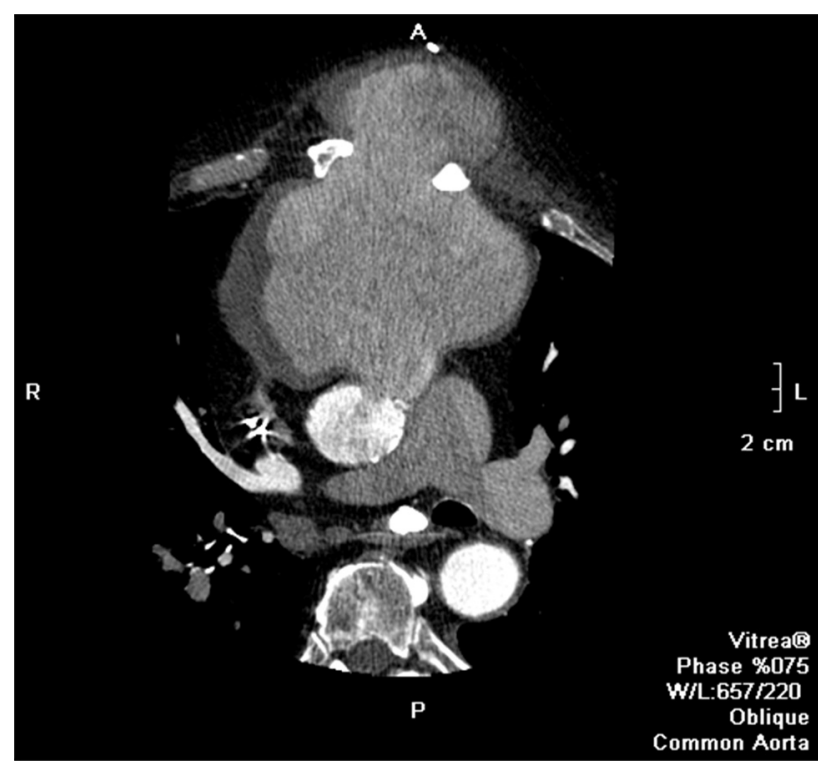

FIGURE 1. Computed tomography shows a patient with an extensive pseudoaneurysm that has eroded through the sternum and lies just under the skin. Reoperation in such cases is fraught with danger, because one must control circulation before sternal reentry to avoid extensive blood loss.

this approach, they reduce the risks associated with deep hypothermia, such as coagulopathy, by cooling only to $25^{\circ} \mathrm{C}$. Further, they avoid the specific risk of left ventricular dilatation, which occurs when hypothermia results in ventricular fibrillation before sternal reentry, by placing a left ventricular vent.

We have to be mindful that when antegrade cerebral perfusion is used in the replacement of the aortic arch, most perioperative strokes are not secondary to a lack of cerebral protection but rather are a consequence of embolization, and that the carotid arteries are prone to atherosclerosis in the patient population needing such surgery. Additionally, the approach excludes the vertebral arteries, which in many patients may be an important source of cerebral arterial inflow, particularly at higher temperatures.

Many complex issues are involved in the surgical treatment of patients with pseudoaneurysms adjacent to the back of the sternum (Figure 1), which often necessitate cannulation for cardiopulmonary bypass and cerebral protection before sternal reentry in such patients undergoing aortic arch replacement, and these issues demand innovative approaches and a diverse armamentarium for the cardiac surgeon. The techniques described by Wehman and colleagues ${ }^{1}$ contribute to that arsenal. One size does not fit all, and there is more than one way to skin a cat.

\section{References}

1. Wehman B, McCormick B, Pham S, Taylor BT. Safe sternal reentry in the setting of a giant aortic pseudoaneurysm and aortic regurgitation. J Thorac Cardiovasc Surg. 2015;149:e94-6.

2. DeBakey ME, Crawford ES, Cooley DA, Morris GC Jr. Successful resection of fusiform aneurysm of aortic arch with replacement by homograft. Surg Gynecol Obstet. 1957;105:657-64.

3. Griepp RB, Stinson EB, Hollingsworth JF, Buehler D. Prosthetic replacement of the aortic arch. J Thorac Cardiovasc Surg. 1975;70:1051-63.

4. Bachet J, Guilmet D, Goudot B, Termignon JL, Teodori G, Dreyfus G, et al. Cold cerebroplegia. A new technique of cerebral protection during operations on the transverse aortic arch. J Thorac Cardiovasc Surg. 1991;102:85-93; discussion 93-4.

5. Kazui T, Washiyama N, Muhammad BA, Terada H, Yamashita K, Takinami M, et al. Extended total arch replacement for acute type a aortic dissection: experience with seventy patients. J Thorac Cardiovasc Surg. 2000;119:558-65.

6. Sabik JF, Lytle BW, McCarthy PM, Cosgrove DM. Axillary artery: an alternative site of arterial cannulation for patients with extensive aortic and peripheral vascular disease. J Thorac Cardiovasc Surg. 1995;109:885-90; discussion 890-1.

7. Urbanski PP. Carotid artery cannulation in acute aortic dissection with malperfusion. J Thorac Cardiovasc Surg. 2006;131:1398-9.

\title{
Lessons learned from a thorny case
}

Isabelle Claudet, MD, MSc, ${ }^{a}$ Camille Bréhin, $\mathrm{MD},{ }^{\mathrm{a}}$ Daniel Roux, $\mathrm{MD},{ }^{\mathrm{b}}$ and Sébastien Hascoët, $\mathrm{MD},{ }^{\mathrm{c}}$ Toulouse, France

\footnotetext{
From the Pediatric Emergency Unit, ${ }^{\text {a }}$ Children's Hospital, CHU Toulouse, Toulouse, France; the Cardiovascular Surgery Unit, ${ }^{\mathrm{b}}$ Rangueil Hospital, CHU Toulouse, Toulouse, France; and the Pediatric Cardiology Unit, ${ }^{\mathrm{c}}$ Children's Hospital, CHU Toulouse, Toulouse, France.

Disclosures: Authors have nothing to disclose with regard to commercial support.

Received for publication Feb 16, 2015; accepted for publication Feb 21, 2015; available ahead of print March 24, 2015.

Address for reprints: Isabelle Claudet, MD, MSc, Pediatric Emergency Department, Children's Hospital, 330 Great Britain Ave, TSA 70034, 31059 Toulouse Cedex 9,

France (E-mail: claudet.i@chu-toulouse.fr).

J Thorac Cardiovasc Surg 2015;149:e97-9

$0022-5223 / \$ 36.00$

Copyright (c) 2015 by The American Association for Thoracic Surgery

http://dx.doi.org/10.1016/j.jtcvs.2015.02.041
}

We report a case of pericardial penetration of a mediumsized cactus spine in a child.

\section{CLINICAL SUMMARY}

A 5.5-year-old boy was admitted to the emergency department of a level I regional hospital after being pushed onto a spiny cactus. He had difficulty breathing and refused to lie down. During transportation his vital signs were as follows: pulse, 111 beats/min; blood pressure, 136/87 mm $\mathrm{Hg}$; and oxygen saturation by finger-probe pulse oximetry, $99 \%$. At hospital admission (6:00 PM), the physical 


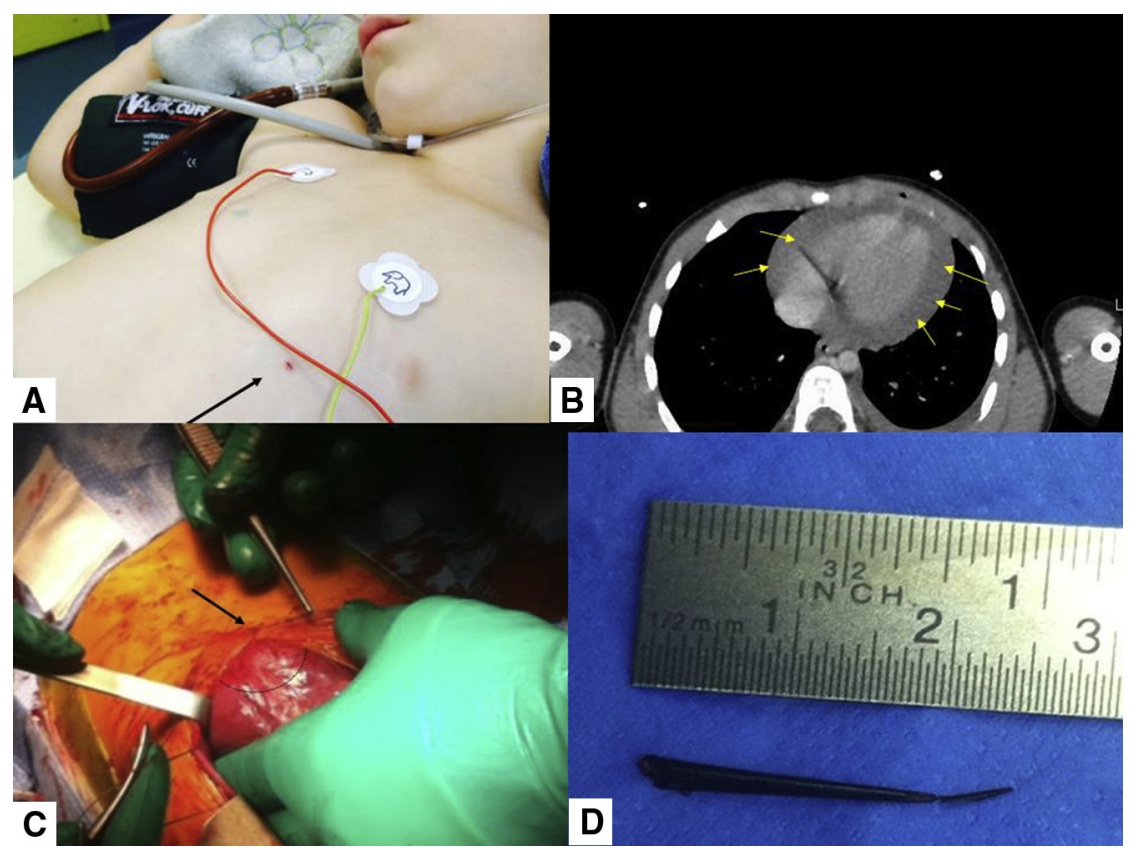

FIGURE 1. A, On admission, a small thoracic entry wound was located on the upper anterior chest. B, After the patient was transferred to a level III pediatric emergency unit, the second thoracic computed tomographic scan showed an important pericardial effusion. C, The sternotomy revealed superficial scratches on the apex of the right ventricle. D, Two pieces of a $3.5-\mathrm{cm}$ long cactus thorn were removed.

examination was only significant for the palpation of foreign bodies on the left knee and the forearm and a small entry wound on the upper anterior chest overlying the sternum (Figure 1, A). A chest radiograph appeared normal. After a surgical advice, the decision was taken not to extract the foreign bodies manually and to let the child go home with a prescription for pain killers and antibiotics. At home, the child refused to eat. He had intense thirst and was described as agitated and plaintive. In the middle of the night, he woke up and fainted; he was driven back to the emergency unit. On admission (4:20 AM), his vital signs were as follows: heart rate, 132 beats/min; blood pressure, 100/59 mm Hg; capillary refill, greater than 3 seconds; oxygen saturation by pulse oximetry, $95 \%$; and capillary hemoglobin value, $10.8 \mathrm{~g} / \mathrm{dL}$. The patient was extremely pale and reported abdominal pain. The physical examination found abdominal distention, enlarged liver with hepatalgia, and tachycardia. Physicians thought the patient had an intra-abdominal injury. Volemic expansion was started with a bolus of normal saline solution (400 mL), followed by a transfusion of $200 \mathrm{~mL}$ of blood red cells (6:00 AM). The basic metabolic panel was remarkable for hyperglycemia $(11 \mathrm{mmol} / \mathrm{L})$ and elevated aspartate aminotransferase (64 UI/L). Serum lactate was $3.1 \mathrm{mmol} / \mathrm{L}$, and cardiac enzyme assay indicated a major increase of troponin $(3590 \mathrm{ng} / \mathrm{mL})$. Complete blood cell count was significant for leukocytosis $\left(22,290\right.$ cells $\left./ \mathrm{mm}^{3}\right)$. Venous blood gas study revealed the following: $\mathrm{pH}, 7.35$; venous $\mathrm{PO}_{2}, 61 \mathrm{~mm} \mathrm{Hg}(8.1 \mathrm{kPa})$; venous $\mathrm{PCO}_{2}, 38 \mathrm{~mm} \mathrm{Hg}$ $(5.1 \mathrm{kPa})$; and bicarbonate $22 \mathrm{mmol} / \mathrm{L}$. There was a global elevation of the ST segment on the electrocardiogram. Echocardiography showed a pericardial effusion with no sign of compression of the right cavities and an ejection fraction of $70 \%$. A minimal left pleural effusion and a perihepatic effusion were identified on a body scan in addition to the pericardial effusion. Because of the critical condition of the child, he was transferred to our level III pediatric university hospital. On arrival (8:35 AM), he had signs of cardiogenic shock and cardiac tamponade. His vital signs were as follows: pulse rate, 133 beats/min; blood pressure, $122 / 73 \mathrm{~mm} \mathrm{Hg}$; respiratory rate, 20 breaths/ min, oxygen saturation by pulse oximetry, $98 \%$; and capillary hemoglobin value, $4 \mathrm{~g} / \mathrm{dL}$. Echocardiography and a second thoracic computed tomographic scan (Figure 1,B) confirmed a voluminous pericardial effusion and showed a transpericardial foreign body. A median sternotomy without extracorporeal circulation was performed. The cactus spine did not penetrate the heart but did create superficial scratches on the apex of the right ventricle (Figure 1,C). Through a pericardiectomy, $200 \mathrm{~mL}$ of blood was evacuated and 2 pieces of a $3.5-\mathrm{cm}$ long cactus thorn were removed (Figure 1,D). During the following days, the patient did well. He was transferred on day 5, after an uncomplicated stay, to Switzerland for recovery. The cactus was identified as an Agave americana "mediopicta alba."

\section{DISCUSSION}

This is the first pediatric description of an intracardiac foreign body involving a cactus spine. A case of a mediastinal penetration was published in 2008 involving a 
4.5-year-old boy who had fallen chest first onto a barrel cactus. ${ }^{1}$ Several pediatric cases of intracardiac or intrapericardial penetration from a sewing needle have been reported. ${ }^{2-4}$ Several lessons should be learned from the present case. First, immediately after injury, children (or adults) may have minimal clinical signs or be symptom free when a foreign body is embedded in the myocardium or in the pericardial space. ${ }^{4}$ The time between penetration and diagnosis can take several hours. ${ }^{2}$ Second, radiography of the chest has usually failed to show any abnormality; most vegetal spines are radiolucent. Computed tomographic scanning has limitations in identifying small foreign bodies and objects with densities similar to surrounding structures. ${ }^{5}$ Third, a small thoracic puncture wound can hide potentially serious cardiac injuries. Finally, treatment options for cardiac foreign body or bodies have to be discussed case by case with cardiovascular surgeons. The presence of symptoms is a primary indication for surgery, especially in cases of cardiac tamponade, and median sternotomy is recommended if pericardiectomy is needed. ${ }^{4}$

\section{CONCLUSIONS}

Intracardiac vegetal spines or needles can be revealed by a 2-phase clinical evolution. This can lead to a delay in appropriate management in a life-threatening situation.

We gratefully acknowledge Mrs Claire Walker for her help in the translation of the manuscript.

\section{References}

1. O’Neill PJ, Sinha M, McArthur RA, Frechette A. Penetrating cactus spine injury to the mediastinum of a child. J Pediatr Surg. 2008;43:e33-5.

2. Perrotta S, Perrotta A, Lentini S. In patients with cardiac injuries caused by sewing needles is the surgical approach the recommended treatment? Interact Cardiovasc Thorac Surg. 2010;10:783-92.

3. Sola JE, Cateriano JH, Thompson WR, Neville HL. Pediatric penetrating cardiac injury from abuse: a case report. Pediatr Surg Int. 2008;24:495-7.

4. Actis Dato GM, Arslanian A, Di Marzio P, Filosso PL, Ruffini E. Posttraumatic and iatrogenic foreign bodies in the heart: report of fourteen cases and review of the literature. J Thorac Cardiovasc Surg. 2003;126:408-14.

5. Lydiatt DD, Hollins RR, Moyer DJ, Davis LF. Problems in evaluation of penetrating foreign bodies with computed tomography scans: report of cases. J Oral Maxillofac Surg. 1987;45:965-8.

\title{
Open chest core needle biopsy of left ventricle in the evaluation of suspected focal myocardial inflammation
}

\author{
Jukka Y. A. Lehtonen, MD, ${ }^{a}$ Janne J. Jokinen, MD, ${ }^{\mathrm{b}}$ Miia Holmström, MD,${ }^{\mathrm{c}}$ and Markku Kupari, MD, ${ }^{\mathrm{a}}$ \\ Helsinki, Finland
}

\begin{abstract}
Although clinical diagnosis is sufficient in most mild and moderate cases of myocarditis, histologic verification and classification by endomyocardial biopsy (EMB) are necessary if the clinical course is fulminant and when cardiac sarcoidosis (CS), giant cell myocarditis (GCM), or eosinophilic myocarditis is suspected. ${ }^{1}$ The well-known weakness of EMB is its limited sensitivity in patchy myocardial involvement. In our experience, a single EMB session detects at best 1 of 5 cases of $\mathrm{CS}^{2}$ and two thirds
\end{abstract}

\footnotetext{
From the Divisions of Cardiology ${ }^{\mathrm{a}}$ and Cardiac Surgery, ${ }^{\mathrm{b}}$ Heart and Lung Center, Helsinki, Finland; and HUS Radiology (Medical Imaging Center), ${ }^{\mathrm{c}}$ Helsinki University Central Hospital, Helsinki, Finland.

Disclosures: Authors have nothing to disclose with regard to commercial support.

Received for publication March 10, 2015; accepted for publication March 16, 2015; available ahead of print April 10, 2015

Address for reprints: Jukka Y. A. Lehtonen, MD, Helsinki University Hospital, Heart and Lung Center, PO Box 340, FI-00029 Helsinki, Finland (E-mail: jukka. lehtonen@hus.fi)

J Thorac Cardiovasc Surg 2015;149:e99-102

$0022-5223 / \$ 36.00$

Copyright (c) 2015 by The American Association for Thoracic Surgery

http://dx.doi.org/10.1016/j.jtcvs.2015.03.016
}

of cases of $\mathrm{GCM}^{3}$ even when targeted with the help of modern cardiac imaging. Biventricular biopsies may increase the diagnostic yield, ${ }^{4}$ as may the use of electrophysiologic mapping ${ }^{5}$ or intracardiac ultrasound ${ }^{6}$ to guide the sampling procedure. Unfortunately, despite repeated EMBs, the diagnosis may remain elusive. ${ }^{2}$

Surgical core needle myocardial biopsy through a left minithoracotomy provides several advantages over EMB in exchange for being more invasive, and therefore it is rarely used today. First and foremost, it gives access to areas of myocardium that are not reachable with a bioptome from inside the ventricular cavities. Further, instead of small endomyocardial samples, it provides full-thickness specimens of the left ventricular (LV) wall, and the possibility of visual inspection and palpation of the epicardial surface may help target the biopsy to areas of abnormal myocardium. We describe 3 patients with focal myocardial disease in whom histologic diagnosis was considered crucial for prognostic assessment and treatment. After multiple nondiagnostic EMBs, open surgical LV biopsy gave the diagnosis in each of them. 